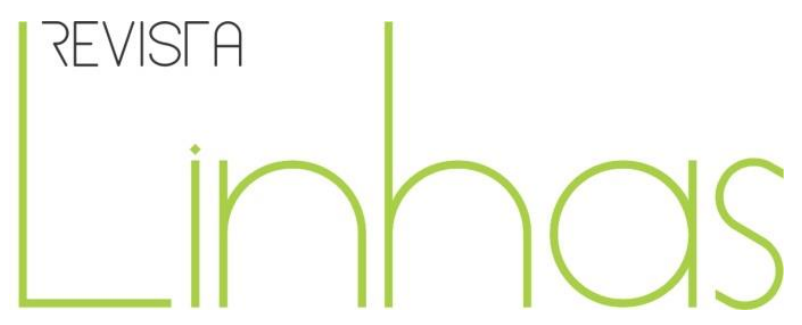

\title{
Narrativas de professores de ciências sobre seu percurso formativo junto ao mestrado acadêmico: mudanças, enfrentamentos e perspectivas
}

\begin{abstract}
Resumo
Trata-se de pesquisa realizada durante os anos de 2016 a 2018 que investigou as relações tecidas entre os professores que realizaram mestrado acadêmico e o retorno à escola e seus afazeres em sala de aula. Para esse momento, apresentamos uma parte do estudo na tentativa de trazer à tona algumas reflexões sobre: $\mathrm{O}$ que muda nessa relação? Como a escola percebe e se prepara para esse retorno? Como o professor entende esse percurso? Objetivo é apresentar o que encontramos nas narrativas dos professores ao mesmo tempo em que chamamos atenção para as tensões entre formação e espaço de trabalho, distanciamentos, mudanças e enfrentamentos que permeiam o fazer mestre no contexto de políticas públicas que nem sempre estão na mesma sintonia. Os estudos (auto)biográficos fizeram parte de nossa caminhada no exercício de uma compreensão interpretativa-narrativa de si e também por nos permitir uma formação refletida/reflexiva nessa tensão de exercitar a relação com a história formativa do outro. Daquilo que fora narrado, a esperança faz parte do dito, do materializado; as expectativas de reconhecimento nem sempre são acolhidas pelo colegas e gestores, os aprendizados são sempre valorosos, o retorno à universidade fora sinalizado como algo bom e necessário, porém o formato do trabalho, a falta de conexões mais profícuas entre a escola/ universidade, professorado/ licenciatura/ formação continuada, aparecem como desafios urgentes para a mudança de perspectiva de entendimento dessa formação ao longo da vida.
\end{abstract}

Palavra-chave: Professores de Ciências. Ensino Fundamental. Formação Continuada. Mestrado Acadêmico.
Talamira Taita Rodrigues Brito

Universidade Estadual do Sudoeste da Bahia - UESB Itapetinga/BA - Brasil taitadoc@gmail.com

Regiane Barreto Martins

Secretaria de Educação do Estado da Bahia - Jequié/BA - Brasil regianex@hotmail.com

\footnotetext{
Para citar este artigo:

BRITO, Talamira Taita Rodrigues; MARTINS, Regiane Barreto. Narrativas de professores de ciências sobre seu percurso formativo junto ao mestrado acadêmico: mudanças, enfrentamentos e perspectivas. Revista Linhas. Florianópolis, v. 20, n. 43, p. 132-160, maio/ago. 2019.
} 


\title{
Narratives of science teachers about their training course with the academic master: changes, constraints and perspectives
}

\begin{abstract}
It is a research carried out during the years 2016 to 2018 that investigated the relations between the teachers who carried out an academic master's degree and the return to school and their chores in the classroom. For this moment we present a part of the study in the attempt to bring up some reflections on: What changes in this relation? How does the school perceive and prepare for this return? How does the teacher understand this course? With the objective of presenting what we find in teachers' narratives, while drawing attention to the tensions between training and work space, distancing, changes and confrontations that permeate the mastering in the context of public policies that are not always in the same tune. The (self) biographical studies were part of our journey in the exercise of an interpretive-narrative understanding of oneself and also by allowing us a reflected / reflexive formation in this tension of exercising the relation with the formative history of the other. Expectations of recognition are not always welcomed by colleagues and managers, the learning always valued, the return to university was signaled as good and necessary, but the format of work, the lack of more proficient connections between school / university, teaching / undergraduate / continuing education, appear as urgent challenges to change the perspective of understanding this formation throughout life.
\end{abstract}

Keyword: Science Teachers. Elementary School. Continuing Education. Academic Master. 
A formação de professores continua sendo uma pauta da ordem do dia. Seja pela implementação de ações provenientes dos Planos Decenais de Educação e seus sistemas, seja pela realidade apresentada por cada um deles em seu cotidiano, ou ainda, pelas necessidades formativas dos professores de maneira continuada através dos cursos de graduação complementares e/ou pós-graduação (lato ou stricto sensu).

Durante os anos de 2016 e 2018, investimos em uma pesquisa junto aos professores da Educação Básica da rede estadual de ensino da Bahia, tomando como referência o município de Jequié . Cinco professoras participaram da etapa de construção das narrativas e será a partir de tais depoimentos que faremos nossas reflexões.

A problemática foi construída a partir de algumas contradições encontradas no seio da escola pública estadual e municipal (anos finais e ensino médio) quanto aos olhares tecidos sobre os professores que são afastados, pelo direito estatutário, para estudos em nível de mestrado e que, uma vez concluídos, retornam para uma escola, que muitas vezes não se preparou para recebê-los e tampouco eles se deram conta do que representou essa formação para sua vida formativa e profissional em termos de "exigência” de outro trato à sua nova condição.

Para o Norte e Nordeste do país, em especial, a expansão e interiorização da pósgraduação no Brasil, nessas duas últimas décadas, trouxe para mais próximo da realidade do professorado da educação básica a possibilidade de fazer mestrados acadêmicos e profissionais. Como reverso dessa situação, ou ainda como consequência desta, a escola passou a receber professores com outra experiência formativa, outras expectativas para trabalhar e pensar sobre seu trabalho e ao retornarem para a escola, esta aparentemente permanece sem nenhum interesse naquele produto construído em dois anos e que, muitas vezes, tem uma relação direta com a realidade daquela comunidade, daquele professorado e o "eco", por sua vez, não acontece.

O professor volta para sua sala de aula, volta para a mesma carga horária que tinha antes de seu regresso, e, as estruturas de trabalho continuam inalteradas. Uma vez que

\footnotetext{
${ }^{1}$ Pesquisa foi desenvolvida através do Programa de Pós-Graduação em Educação Científica e Formação de Professores (PPGECFP) da Universidade Estadual do Sudoeste da Bahia. Apoio Grupo Impressões - estudo e pesquisa em Desenvolvimento Profissional de professores: trabalho, narrativa e memória formativa.
} 
isso fora constatado no dia a dia de fazer escola em discursos de professores, percebe-se também que a única coisa material, de fato consolidada, é o aumento de percentual em seus proventos por agregar um título.

Essa realidade observada por nós tem sido cada vez mais comum, e atravessada por uma série de questionamentos que extrapolam o pedagógico, em termos de ganho na formação, e apensam questões do tipo: como a escola/município/estado se preparam para receber aquele título? Para além do aumento salarial, como o professor mestre entende sua relação com a titulação? O que muda?

Tais provocações nos apresentaram um resultado de pesquisa que, por ora, trataremos da seguinte forma: num primeiro momento, uma discussão teórica no campo da formação inicial e continuada de professores de ciências e disputas políticas; num segundo momento, apresentaremos o que os professores narram sobre a relação construída a partir desse "voltar mestre para as escolas"; e, por fim, apontamos algumas considerações sobre o que representou o resultado dessa parte da pesquisa e sua contribuição para refletir e edificar políticas outras para o entendimento e acolhimentos de professores nessa fase da profissão e da formação.

\section{Mudanças... a profissão e a formação do professor de ciências no Brasil}

Uns, com os olhos postos no passado, Vêem o que não vêem: outros, fitos Os mesmos olhos no futuro, vêem

O que não pode ver-se. (Trecho do poema "Colhe o dia, porque és ele" Ricardo Reis/heterônimos do escritor Fernando Pessoa)

\section{Lembrando aspectos da história...}

O sistema educacional brasileiro, ao longo das três últimas décadas, tem passado por reformas políticas que objetivaram contemplar novas demandas do mercado de trabalho, a valorização de tipos de formações, bem como, o atendimento a interesses de grupos políticos. Tais questões são consequências das transformações econômicas, culturais e políticas, globais e nacionais, que incidem sobre o entendimento da profissão 
do professor, dos processos formativos e da atuação docente (ROMANELLI, 1978 apud NARDI; CORTELA, 2015).

A formação inicial é um componente de fundamental importância no movimento que engloba a profissão dos professores. É entendida como o processo de formação de profissionais para atuarem no ensino básico, no qual deve ser possibilitado aos futuros profissionais da educação o desenvolvimento de competências e habilidades, por meio dos conhecimentos pedagógicos e específicos, oriundos de uma instrução formal obtida em instituições de ensino superior e devidamente certificadas (MELO; LUZ, 2005).

Pérez (1999) complementa, afirmando que esse primeiro momento formativo deve também promover nos futuros professores o entendimento da necessidade de se atualizar, a respeito de novas estratégias, métodos, técnicas, ferramentas, de modo individual e coletivo, em um processo de reflexão sobre a prática, e assim, atender às transformações que incidem sobre a escola.

Saviani (2009) destaca que a formação para professores no Brasil passa a ser entendida como necessária após a independência do país, quando se começa a pensar em uma educação popular. Contudo, o ofício de professor passa a ser considerado em nível superior somente em 1934, quando a Universidade de São Paulo incorpora o Instituto de Educação, que se transforma na Seção de Educação da Faculdade de Filosofia, Ciências e Letras.

Até os anos 1960, atuavam como professores da educação básica profissionais das mais diversas áreas, em decorrência da falta de profissionais com formação apropriada e, também em função de um sistema educacional que tinha como direcionamento, basicamente, a transmissão de conhecimentos de modo tradicional, no qual se priorizava a repetição e memorização dos conteúdos (CORTELA, 2011).

Esse cenário era propício ao entendimento de que qualquer indivíduo com conhecimento em uma determinada área, ainda que mínimo, poderia atuar de modo satisfatório em sala de aula.

Foram as tensões políticas entre as duas maiores potências da época, Estados Unidos da América e a extinta União Soviética, que promoveram o desenvolvimento da 
indústria bélica e a corrida área espacial, o que resultou na divulgação, expansão e popularização das Ciências em todo o mundo.

A primeira Lei de Diretrizes e Bases da Educação Nacional, Lei 4.024/61 (LDB 4.024/61), foi aprovada apenas três anos antes da implementação da Ditadura Militar no Brasil. Nesse período, o país passava por momentos de turbulência social, política e econômica, também consequências do contexto político internacional, que resultaram na perda da democracia a partir de 1964. Em seu texto, a LDB 4.024/61, em consonância com o contexto social das décadas de 1960 e 1970, propôs normas de como o sistema educacional brasileiro deveria estar organizado. Buscava promover e ampliar a oportunidade de escolarização, quando a educação escolar passou a "[...] ser considerada como direito e responsabilidade tanto do poder público como da iniciativa privada [...]" (NARDI; CORTELA, 2015, p. 16), na tentativa de diminuir as desigualdades sociais existentes no país. Naquele período,

[...] a Educação foi organizada em níveis: Primário (4 anos obrigatório) e Secundário, subdividido em Ginasial (4 anos) e Colegial (3 anos). Para este último, eram três opções possíveis: o Normal, o Clássico e o Científico. O primeiro era destinado àqueles alunos que pretendiam ser professores no ensino primário, chamado de "normalistas"; o segundo e o terceiro, destinados aos alunos que queriam seguir seus estudos em cursos superiores, nas áreas de ciências humanas, ciências exatas e biológicas, respectivamente. (NARDI E CORTELA, 2015, p. 18)

Esse documento também reorganizou e normatizou a formação e o exercício da profissão professor, com requisitos mínimos para que os profissionais de educação pudessem atuar em sala de aula. A LDB 4.024/61, em seu capítulo V, discorre a respeito dessas questões:

Art. 53. A formação de docentes para o ensino primário far-se-á:

a) em escola normal de grau ginasial no mínimo de quatro séries anuais onde além das disciplinas obrigatórias do curso secundário ginasial será ministrada preparação pedagógica;

b) em escola normal de grau colegial, de três séries anuais, no mínimo, em prosseguimento ao vetado grau ginasial.

Art. 56. Os sistemas de ensino estabelecerão os limites dentro dos quais os regentes poderão exercer o magistério primário.

Art. 59. A formação de professores para o ensino médio será feita nas faculdades de filosofia, ciências e letras e a de professores de disciplinas 
específicas de ensino médio técnico em cursos especiais de educação técnica. (BRASIL, 1961, p. 10)

Tal LDB passou por duas reformas, Lei 5.692/1971 e Lei 7.044/1982, antes da promulgação da LDB de 1996, a Lei 9.394/96. Essas mudanças buscavam atender a linha do governo que estava sob o regime militar, instaurado no Brasil desde 1964. É nesse contexto que o país firma contratos e acordos com órgãos internacionais que tinham como intenção o controle do sistema educacional, dos profissionais da educação e, consequentemente, da população, associado a ganhos financeiros para o grupo que estava no poder. O MEC-USAID, principal acordo firmado entre o Brasil e os Estados Unidos, não promoveu mudanças significativas para a melhoria da qualidade do ensino brasileiro, mas influenciou reformas voltadas para o ensino de $1^{\circ}$ e $2^{\circ}$ graus, bem como para a formação universitária (NARDI; CORTELA, 2015).

Em 1982, a Lei 7.044/1982, propôs mudanças no que se refere ao ensino de $1^{\mathrm{a}}$ a $4^{\mathrm{a}}$ séries, em que era exigida apenas a formação em nível de $2^{\circ}$ grau, mantendo as orientações para os demais níveis de ensino, ou seja, há uma progressão no entendimento da relação entre a formação dos professores e os níveis de formação tidos como adequados para cada fase de escolaridade. São alterações discretas e ocorridas em um intervalo de tempo razoavelmente longo, mas que começaram a produzir as primeiras reflexões sobre os cursos de Licenciatura e na formação de professores.

Em 1996 foi promulgada a atual LDB, lei 9.394/96, no período após a redemocratização do Brasil e após a promulgação da Constituição de 1988 que traz explicitado em seu texto o dever do Estado em oferecer educação gratuita e de qualidade para todos os brasileiros, sendo esse um direito constitucional.

A LDB 9.394/96 promoveu alterações pertinentes no entendimento sobre os requisitos necessários à atuação no magistério, dentro de cada nível, além de apontar como deveria ser a formação dos profissionais da educação. O estágio tem em sua carga horária um total de 40oh, e passa a ser compreendido como fundamental para o processo formativo dos futuros professores, distribuído durante os cursos de licenciatura, de modo a transpor o modelo 3+1, aproximando os conhecimentos teóricos e práticos. A formação inicial em nível superior passa a ser necessária para os docentes, 
inclusive para os que já estavam em atuação, bem como processos formativos contínuos. Nardi e Cortela (2015) ressaltam que a LDB 9.394/96, ao mesmo tempo, contemplou e conciliou alguns interesses internacionais e as demandas sociais do referido período.

Essa legislação culminou na necessária reestruturação dos cursos voltados à formação de professores, o que foi proposto e implementado pelo Conselho Nacional de Educação/Conselho Pleno (CNE/CP 01/2002), que estabeleceu as Diretrizes Curriculares Nacionais para a Formação de Professores da Educação Básica em nível superior, em cursos de graduação plena. As licenciaturas passaram por um processo de reestruturação, com a elaboração de um currículo formativo mais próximo à docência e à educação básica, com a inserção de disciplinas mais direcionadas ao ofício do magistério, reforçando a obrigatoriedade dos estágios, em um tempo razoável, articulados com as disciplinas específicas, próprias de cada área de formação.

Nesse contexto, a formação inicial como preparação profissional tem papel crucial para possibilitar que os professores se apropriem de determinados conhecimentos e possam experimentar, em seu próprio processo de aprendizagem, o desenvolvimento de competências necessárias para atuar nesse novo cenário. A formação de um profissional de educação tem que estimulá-lo a aprender o tempo todo, a pesquisar, a investir na própria formação e a usar sua inteligência, criatividade, sensibilidade e capacidade de interagir com outras pessoas. (BRASIL, 2000, p. 13)

As universidades se adequam a essa nova realidade, e, juntamente com o os governos federais e estaduais, passam a ofertar cursos de formação para os professores que ainda não possuem a graduação, mas que já estavam inseridos no ensino básico. Para tal, são pensadas estratégias, como ofertas de cursos diferenciados e que respeitem a realidade dos docentes, com base na meta referente ao artigo 62 da Lei 9394/96, que busca a totalidade dos professores com nível superior atuando nas escolas de todo o país.

Melhorar a formação docente implica instaurar e fortalecer processos de mudança no interior das instituições formadoras, respondendo aos entraves e aos desafios apontados. Para isso, não bastam mudanças superficiais. Faz-se necessária uma revisão profunda dos diferentes aspectos que interferem na formação inicial de professores, tais como: a organização institucional, a definição e estruturação dos conteúdos para que respondam às necessidades da atuação do professor, os processos formativos que envolvem aprendizagem e desenvolvimento das 
competências do professor, a vinculação entre as escolas de formação inicial e os sistemas de ensino. (BRASIL, 2000, p. 12)

Em 2015, a segunda resolução do Conselho Nacional de Educação - Conselho Pleno (CNE /CP 02/2015) foi promulgada. Esse documento traz um entendimento mais amplo a respeito da docência do professor, que passa a ser compreendida em seu artigo 2, como:

$\S 1^{\circ}$ Compreende-se a docência como ação educativa e como processo pedagógico intencional e metódico, envolvendo conhecimentos específicos, interdisciplinares e pedagógicos, conceitos, princípios e objetivos da formação que se desenvolvem na construção e apropriação dos valores éticos, linguísticos, estéticos e políticos do conhecimento inerentes à sólida formação científica e cultural do ensinar/aprender, à socialização e construção de conhecimentos e sua inovação, em diálogo constante entre diferentes visões de mundo.

$\S 2^{\circ}$ No exercício da docência, a ação do profissional do magistério da educação básica é permeada por dimensões técnicas, políticas, éticas e estéticas por meio de sólida formação, envolvendo o domínio e manejo de conteúdos e metodologias, diversas linguagens, tecnologias e inovações, contribuindo para ampliar a visão e a atuação desse profissional. (BRASIL, 2015, p. 3)

A docência, portanto, deve atender as novas demandas do contexto escolar, fomentadas pelas mudanças e transformações sociais, as quais promoveram novas relações entre professores, alunos, comunidade escolar e sociedade. Desse modo, ao professor compete motivar uma aprendizagem pautada na liberdade de aprender, permeada pelo espírito investigativo, fomentar o prazer em aprender e, consequentemente, a permanência de seus alunos na escola. Cabe a esse profissional, ainda, uma educação em que a pluralidade e a diversidade presentes nas salas de aula sejam respeitadas por todos os envolvidos no processo de ensino, por meio da tolerância às diferenças de gênero, religião e cultura, que são pronunciadas nesse documento "[...] como princípios vitais para a melhoria e democratização da gestão e do ensino [...]" (BRASIL, 2015, p. 1).

Esse documento busca abordar relações entre a formação inicial, valorização do magistério e a formação continuada para quem já possui a licenciatura e está atuando, de modo a possibilitar a melhoria da educação básica em um “[...] processo dinâmico e complexo, direcionado à melhoria permanente da qualidade social da educação e à valorização profissional [...]" (BRASIL, 2015, p. 4), e, para tal, o texto defende de modo 
pontual a formação continuada como necessária e imperativa dentro das políticas públicas educacionais, como vieses de retomada da formação pelos professores, que pode por meio desses processos reconfigurar os conhecimentos obtidos tanto na formação inicial quanto os saberes desenvolvidos durante a prática de sua docência.

\section{Políticas públicas para a formação continuada no Brasil}

Os cursos de licenciatura têm se lançado ao desafio de promover uma formação mais próxima da realidade escolar. Contudo, esse processo formativo não tem acompanhado a velocidade das transformações sociais e culturais vividas nas escolas, fato que sempre resultará em algumas lacunas em relação à formação inicial e à prática pedagógica dos professores.

Chimentão (2009) chama atenção para as exigências que recaem sobre a profissão docente, pois é requerida desses profissionais uma bagagem de conhecimentos sempre atualizados a respeito dos conteúdos específicos e, também, em relação às mudanças sociais, o que vai além do espaço da sala de aula, mas que incidem sobre o processo formativo dos alunos. Essa autora ainda fala da "[...] importância da capacitação dos profissionais da educação por meio da formação continuada". Cunha e Krasilchik (2000) destacam que esse processo formativo pode "[...] garantir a atualização dos professores, como também suprir deficiências dos cursos de formação. [...]" (CUNHA; KRASILCHIK, 2000, p. 2).

A formação continuada é compreendida por Chimentão (2009) como um processo no qual os saberes inerentes à atuação do professor, obtidos com a formação inicial, são aperfeiçoados, melhorados, podem resultar em práticas que promovam a melhoria da qualidade de ensino e, consequentemente, a mudança do educador sobre suas práticas a partir da reflexão de seu percurso formativo e no campo de trabalho. Essa autora complementa dizendo que:

Fica mais difícil de o professor mudar seu modo de pensar o fazer pedagógico se ele não tiver a oportunidade de vivenciar novas experiências, novas pesquisas, novas formas de ver e pensar a escola. [...] para aqueles profissionais que já estão atuando, há pouco ou muito tempo, ela se faz relevante, uma vez que o avanço dos conhecimentos, 
tecnologias e as novas exigências do meio social e político impõem ao profissional, à escola e às instituições formadoras, a continuidade, 0 aperfeiçoamento da formação profissional. (CHIMENTÃO, 2009, p. 6)

A formação continuada para professores ganha destaque no cenário educacional brasileiro no final da década de 1990 e início dos anos 2000, em virtude do aumento e direcionamento de cursos que buscavam promover formação aos professores que já estão no campo de trabalho, em acolhimento à LDB 9.394/96.

No ano de 2004, uma rede de aperfeiçoamento foi lançada pelo governo federal com o intuito de garantir o acesso dos professores da rede pública de ensino, e sem a formação em nível superior, em cursos de licenciatura, para que obtivessem graduação em suas áreas de atuação. Essa rede também contemplou cursos de formação continuada como especialização e mestrado (BRASIL, 2006). Gatti e Barreto corroboram afirmando que:

A proposta é "organizarem regime de colaboração entre União, os Estados, o Distrito Federal e os Municípios, a formação inicial e continuada dos profissionais do magistério para as redes públicas da educação básica" (art. $1^{\circ}$ ). Enseja apoiar "a oferta e a expansão de cursos de formação inicial e continuada a profissionais do magistério pelas instituições públicas de educação superior". E equalizar nacionalmente as "oportunidades de formação inicial e continuada dos profissionais do magistério" (art. $3^{\circ}$, incisos II e III). (GATTI; BARRETO, 2009, p. 51)

Assim, problemas concretos das redes inspiraram iniciativas chamadas de continuada, especialmente na área pública, pela constatação, por vários meios (pesquisas, públicos, avaliações), de que os cursos formação básica dos professores não vinham (e vêm) propiciando adequada base para sua atuação profissional. Muitas das iniciativas públicas de continuada no setor educacional adquiriram, então, a feição de programas compensatórios e propriamente de atualização e aprofundamento avanços do conhecimento, sendo realizados com finalidade de suprir aspectos da má-formação alterando o propósito inicial dessa educação posto nas discussões internacionais -, que seria aprimoramento de profissionais nos avanços, renovações e inovações de suas áreas, dando sustentação à sua criatividade pessoal e à de grupos profissionais, em função dos rearranjos nas produções científicas, técnicas e culturais. (GATTI, 2008, p. 60) 
No ano de 2001, o Plano Nacional de Educação (PNE 2001-2010²) foi elaborado e implementado pelo Ministério da Educação e Cultura - MEC, sendo reestruturado em 2010 e, posteriormente, em 2015. Esse documento destaca e relaciona a carência de professores de Ciências à qualidade de ensino, sendo esse o fator de entrave no funcionamento e expansão do sistema educacional, então vigente. Assinala ainda à necessidade de fomentar a formação de professores nessa área de conhecimento, bem como, à adequação de espaços destinados a aulas de ciências, laboratórios, nas unidades de ensino médio (BRASIL, 2001).

O PNE 2001-2010 apresentou diversas estratégias e metas que tinham como intuito a melhoria da qualidade da educação básica. Nesse sentido, o documento propõe o fomento à formação inicial e continuada de professores para a alfabetização de crianças, a ampliação a programas de iniciação à docência de estudantes dos cursos de licenciatura, para que esses possam aprimorar a formação dos mesmos, que irão atuar na educação básica, bem como buscam reestruturar os cursos de licenciatura:

\section{Art. $1^{\circ}$}

A carga horária dos cursos de Formação de Professores da Educação c comuns:

I - 400 (quatrocentas) horas de prática como componente curricular, vivenciadas ao longo do curso;

II - 400 (quatrocentas) horas de estágio curricular supervisionado a partir do início da segunda metade do curso;

III - 1800 (mil e oitocentas) horas de aulas para os conteúdos curriculares de natureza científico-cultural;

IV - 200 (duzentas) horas para outras formas de atividades acadêmicocientífico-culturais.

Parágrafo único. Os alunos que exerçam atividade docente regular na educação básica poderão ter redução da carga horária do estágio curricular supervisionado até o máximo de 200 (duzentas) horas. (BRASIL, 2000, p. 1)

A formação inicial de professores que atuam fora de sua área de graduação foi contemplada em programas como o Plano Nacional de Formação de Professores da Educação Básica (PARFOR) que foi criado a partir do decreto 6.755, de 29 de janeiro de 2009, e tem por objetivo "[...] organizar as demandas e ofertas dos cursos de formação inicial e continuada do país até o ano de 2014, tendo como meta alcançar os 600 mil

\footnotetext{
${ }^{2}$ Disponível em: <http://portal.mec.gov.br/arquivos/pdf/L10172.pdf>. Acesso em: 05 fev. 2019.
} 
professores das redes públicas que não têm formação adequada. [...]" (MORORÓ, 2012, p. 3510).

Urzetta e Cunha (2013) destacam que nesse tipo de formação as práticas de sala de aula, as atividades diárias das escolas são relacionadas aos conhecimentos teóricos, e essa associação entre o teórico e o prático pode auxiliar, de modo significativo, o desenvolvimento profissional dos professores. Desse modo, Imbernón (2006) destaca:

A formação do professor deve estar ligada a tarefas de desenvolvimento curricular, planejamento de programas e, em geral, melhoria da instituição educativa, e nelas implicar-se, tratando de resolver situações problemáticas ou específicas relacionadas ao ensino em seu contexto. (IMBERNÓN, 2006, p. 17)

O PNE foi reformulado no ano de 2015 e sua vigência passou a ser de 2014-2024, mas as preocupações em relação à formação dos professores permanecem no programa, por meio de parcerias entre instituições de educação de ensino superior, públicas e privadas, de forma orgânica e articulada às políticas de formação dos Estados, do Distrito Federal e dos Municípios propostos (BRASIL, 2015).

Diante dessa demanda, ocorreu o crescimento considerável dos cursos de curta duração no Brasil, em grande parte com caráter tecnicista, oferecidos por instituições particulares e públicas para os docentes que já estavam atuando em sala de aula. Gatti salienta que:

O surgimento de tantos tipos de formação não é gratuito. Tem base histórica em condições emergentes na sociedade contemporânea, nos desafios colocados aos currículos e ao ensino, nos desafios postos aos sistemas pelo acolhimento cada vez maior de crianças e jovens, nas dificuldades do dia-a-dia nos sistemas de ensino, anunciadas e enfrentadas por gestores e professores e constatadas e analisadas por pesquisas. Criaram-se o discurso da atualização e o discurso da necessidade de renovação. (GATTI, 2008, p. 3)

A formação lato sensu, as especializações, também estão inseridas nessa perspectiva, na modalidade presencial ou a distância, promovidas pelas parecerias com governos Estaduais, Municipais e Federal. Gatti complementa afirmando que: 
Seria uma formação dos professores em exercício propiciando-lhes a titulação adequada a seu cargo, que deveria ser dada nos cursos regulares, mas que lhe é oferecida como um complemento de sua formação, uma que já está trabalhando na rede. São projetos elaborados sob a coordenação do poder público, dentro especificações bem definidas. Citemos alguns desses projetos, com grande volume de participantes. (GATTI, 2008, p. 71)

As Diretrizes Curriculares Nacionais para formação de professores de 2015 (CNE/CP $02 / 2015)^{3}$, ressalta em seu texto a importância da formação continuada de professores em todos os níveis de atuação docente, e apresenta no capítulo VI, Art. 16, o seguinte entendimento para essa formação:

A formação continuada compreende dimensões coletivas, organizacionais e profissionais, bem como o repensar do processo pedagógico, dos saberes e valores, e envolve atividades de extensão, grupos de estudos, reuniões pedagógicas, cursos, programas e ações para além da formação mínima exigida ao exercício do magistério na educação básica, tendo como principal finalidade a reflexão sobre a prática educacional e a busca de aperfeiçoamento técnico, pedagógico, ético e político do profissional docente. (BRASIL, 2015, p. 13)

Essa formação, segundo o documento, deve, entre outras coisas, estimular o desenvolvimento profissional dos professores que estão na educação básica, promover a aquisição de novos saberes e competências que possam auxiliar esses profissionais na resolução de problemas e desafios vivenciados em suas unidades de ensino, promover uma formação que permita um ensino que contemple as ciências e as tecnologias presentes na sociedade atual, por meio de práticas mais reflexivas e críticas, pautadas na compreensão da autonomia e protagonismo, próprios da atuação docente. A formação continuada ainda deve buscar a melhoria das ações didáticas, por meio de parcerias em seu ambiente escolar, bem como em outras instâncias educativas e articular o ensino e a pesquisa (BRASIL, 2015, p. 14).

Esse documento também apresenta as atividades e/ou cursos que podem ser entendidos como formação continuada para professores, os quais se diferem em suas intencionalidades, carga horária e instituições às quais devem estar atrelados. Os cursos

3 Disponível em: <http://www.observatoriodopne.org.br/uploads/reference/file/439/documentoreferencia.pdf >. Acesso em: 05 fev. 2019. 
de aperfeiçoamento e atualização ocorrem de modo mais rápido e direto, quase sempre voltados a um treinamento, de um novo recurso ou metodologia. Têm duração média de 2oh - 120h e são, muitas vezes, oferecidos pelos próprios órgãos educacionais, ou em parceria com instituições privadas (BRASIL, 2015, p. 14).

As atividades ou cursos de extensão ocorrem por meio de instituição de educação superior, sendo esse tipo de formação interligado ao ensino e pesquisa desenvolvidos pelas universidades, por meio de grupos de estudos, congressos, encontros, simpósios, e atividades diversas, em uma carga horária mais flutuante. Os cursos de aperfeiçoamento têm por objetivo promover uma melhoria na atuação do profissional dos professores que estão em plena atividade em sala de aula.

A formação em nível de especialização, ou lato sensu, deve ter carga horária mínima de 36oh. O mestrado e o doutorado, assim como a especialização, também devem ser oferecidos por universidades formadoras, mas essas possibilitam a obtenção da titulação de especialista, mestre ou doutor.

O stricto sensu contempla a formação no mestrado - profissionais e acadêmicos -, e no doutorado e apontam para o “[...] desenvolvimento da produção intelectual comprometida com o avanço do conhecimento e de suas interfaces com o bem econômico, a cultura, a inclusão social e o bem-estar da sociedade [...]" (BRASIL, 2017, p. 4). Já o mestrado profissional tem por objetivo uma formação mais técnica, em que se promova uma qualificação e capacitação "[...] mediante o estudo de técnicas, processos, ou temáticas [...] voltados para um campo de conhecimento e atuação em específico" (BRASIL, 2014, p. 1). Ribeiro ressalta ainda que:

A principal diferença entre o mestrado acadêmico (MA) e o MP é o produto, isto é, o resultado almejado. No MA, pretende-se pela imersão na pesquisa formar, a longo prazo, um pesquisador. No MP, também deve ocorrer a imersão na pesquisa, mas o objetivo é formar alguém que, no mundo profissional externo à academia, saiba localizar, reconhecer, identificar e, sobretudo, utilizar a pesquisa de modo a agregar valor a suas atividades, sejam essas de interesse mais pessoal ou mais social. Com tais características, o MP aponta para uma clara diferença no perfil do candidato a esse mestrado e do candidato ao mestrado acadêmico. (RIBEIRO, 2005, p. 8) 
Segundo a CAPES, em sua última avaliação, de 2017, no Brasil foram registrados um total de 4.564 programas de pós-graduação, devidamente reconhecidos e avaliados, que estão distribuídos entre Mestrado Acadêmico, Mestrados Profissionais e Doutorado, com as maiores concentrações nas regiões Sudeste, Sul, Nordeste, Centro-Oeste e Norte, respectivamente. O quadro a seguir ilustra essa distribuição.

Quadro 1: Programas de pós-graduação avaliados e reconhecidos pela CAPES

\begin{tabular}{|c|c|c|c|c|c|c|c|}
\hline \multirow[b]{2}{*}{ Região } & \multicolumn{7}{|c|}{ Total de Programas de pós-graduação } \\
\hline & Total & ME & DO & MP & DP & ME/DO & MP/DP \\
\hline CENTRO-OESTE & 379 & 141 & 11 & 58 & 0 & 169 & 0 \\
\hline NORDESTE & 937 & 391 & 20 & 162 & 1 & 364 & 3 \\
\hline NORTE & 266 & 124 & 3 & 52 & 0 & 87 & 3 \\
\hline SUDESTE & 1981 & 395 & 42 & 382 & 1 & 1162 & 10 \\
\hline SUL & 977 & 294 & 13 & 161 & 0 & 509 & 6 \\
\hline Totais & 4564 & 1345 & 89 & 815 & 2 & 2291 & 22 \\
\hline \multirow{2}{*}{$\begin{array}{l}\text { Cursos Avaliados e } \\
\text { Reconhecidos UF }\end{array}$} & & & Total de & ramas & $s-g r$ & & \\
\hline & Total & ME & DO & MP & DP & ME/DO & MP/DP \\
\hline $\mathrm{BA}$ & 201 & 73 & 5 & 43 & 0 & 80 & 0 \\
\hline \multirow{2}{*}{ Região } & \multicolumn{7}{|c|}{ Total de Cursos de pós-graduação } \\
\hline & \multicolumn{2}{|l|}{ Total } & ME & DO & \multicolumn{2}{|c|}{ MP } & DP \\
\hline CENTRO-OESTE & 548 & & 310 & 180 & \multicolumn{2}{|c|}{58} & 0 \\
\hline NORDESTE & 1304 & & 755 & 384 & \multicolumn{2}{|c|}{165} & 4 \\
\hline NORTE & 358 & & 211 & 91 & \multicolumn{2}{|c|}{56} & 3 \\
\hline SUDESTE & 3153 & & 1557 & 1204 & \multicolumn{2}{|c|}{392} & 11 \\
\hline SUL & 1492 & & 803 & 522 & \multicolumn{2}{|c|}{167} & 6 \\
\hline Totais & 6879 & & 3636 & 2381 & \multicolumn{2}{|c|}{838} & 24 \\
\hline \multirow{2}{*}{$\begin{array}{c}\text { Cursos Avaliados e } \\
\text { Reconhecidos } \\
\text { UF }\end{array}$} & \multicolumn{7}{|c|}{ Total de Cursos de pós-graduação } \\
\hline & \multicolumn{2}{|l|}{ Total } & $\mathrm{ME}$ & DO & & & DP \\
\hline $\mathrm{BA}$ & 281 & & 153 & 85 & & & 0 \\
\hline $\begin{array}{l}\text { Legenda: ME: Mes } \\
\text { Doutorado Profissi } \\
\text { Profissional e Douto }\end{array}$ & $\begin{array}{l}\text { Acad } \\
\text { ME/DO } \\
\text { Profissi }\end{array}$ & O; D & $\begin{array}{l}\text { Douto } \\
\text { Acadê }\end{array}$ & $\begin{array}{l}\text { Acadêr } \\
\text { e Dou }\end{array}$ & & $\begin{array}{l}\text { trado } \\
\text { ico; N }\end{array}$ & $\begin{array}{l}\text { sional; } \\
\text { Mest }\end{array}$ \\
\hline
\end{tabular}

Fonte: Elaborado pelas autoras com base na Plataforma Sucupira ${ }^{4}, 2018$.

Os dados obtidos no último levantamento chamam atenção para o aumento dos cursos, principalmente para os mestrados acadêmicos e profissionais na área de educação, em torno de 25\% (2011-2016). Os mestrados profissionais (MP) na área da

\footnotetext{
${ }^{4}$ Brasil, Ministério da Educação. Plataforma Sucupira. Coordenação de Aperfeiçoamento de Pessoal de Nível Superior. Brasília: 2018. Disponível em: <https://sucupira.capes.gov.br/sucupira/public/consultas/coleta/programa/quantitativos/quantitativoRegiao .jsf;jsessionid=IpC19tcuSCVdbQWNHKsjYjWE.sucupira-213>. Acesso em: 05 de junho de 2018.
} 
educação buscam propiciar uma formação de professores a partir das práticas de ensino e com os mestrandos inseridos no campo de atuação.

André (2017) afirma que o mestrado profissional foi iniciado tardiamente, no ano de 2009, no campo educacional brasileiro, pois este foi visto com estranhamento, uma vez que seu caráter mais prático e aplicável sugeria que o mesmo não privilegiava a pesquisa, com rigor científico, e não possibilitaria mudanças nas concepções sobre o ensino e a prática docente dos professores pesquisadores. Entretanto, essa autora complementa que o mestrado profissional apresenta como vantagem o fato de estar diretamente voltado para a realidade escolar, o que pode auxiliar na produção de novas e mais eficientes possibilidades para superação de problemas próprios da educação básica. Já o mestrado acadêmico constrói investigações que nem sempre estão bem alinhadas com as questões dos contextos das escolas. Ela ainda afirma que, no que tange a estruturação e desenvolvimento, rigor científico, planejamento e estudos dentro da pesquisa, esses mestrados se aproximam significativamente.

A Bahia registra 201 programas de mestrados e doutorado, sendo oferecidos 153 cursos de mestrado acadêmico, 43 profissionais e 85 doutorados entre instituições públicas e privadas. A Universidade Estadual do Sudoeste da Bahia possui 17 programas de pós-graduação, dos quais 05 ofertam o doutorado. Temos 04 mestrados profissionais. Dos mestrados acadêmicos, 03 são voltados para a área de educação e ensino; entre estes últimos, o Mestrado em Educação Científica e Formação de Professores, vinculado ao Programa de Pós-Graduação do Departamento de Ciências Biológicas, campus Jequié, o lócus desta pesquisa.

Os planos de carreira do magistério, sejam nas instâncias federais, estaduais ou municipais, em consonância com a LDB 9.394/1996, vinculam a obtenção dessas formações continuadas (especialização, mestrado e doutorado) a promoções na carreira, quase sempre traduzidas em ganhos financeiros, incorporados aos salários dos professores, que podem variar em suas porcentagens de uma classe para outra ${ }^{5}$. Ainda segundo essa legislação, bem como os documentos oficiais que regem a carreira do

\footnotetext{
${ }^{5}$ Os professores efetivos, em alguns estados, são categorizados em "padrões" que correspondem ao tempo de exercício na rede de ensino. Quanto maior o tempo em atividade, mais elevado é o padrão, que incide diretamente sobre o salário-base e as gratificações oriundas de cursos de aperfeiçoamento, ou até mesmo, mudança no nível de formação.
} 
professor, é garantido o direito de afastamento para realização de cursos de aperfeiçoamento profissional

Em 2016, o governo do Estado da Bahia promulgou o decreto 16.417, de 16 de novembro de 2015, no qual foi suspensa a concessão de licenças aos servidores públicos estaduais para a realização de cursos de qualificação, com base na lei da responsabilidade fiscal e contenção de despesas. Contudo, as condições de melhoria salarial continuaram atreladas, entre outras coisas, à mudança de nível e classe/padrão do professor, que só é possível de se obter por meio da participação em cursos.

Essas reflexões se fazem necessárias para que possamos promover uma análise mais próxima dos significados e sentidos apresentados pelas professoras participantes das pesquisas em suas narrativas a respeito de seus processos de formação inicial, encontro com a docência, permanência na profissão, e a busca para superar os desafios de seu cotidiano, caminhar no mestrado e o regressar para a sala de aula.

\section{Narrativas de professores de ciências junto ao mestrado acadêmico: mudanças...}

\section{O retornar para a escola!}

A profissão professor sempre esteve associada a um local de trabalho, de sujeições, para os professores se manterem na profissão e na área que escolhemos para atuar, mas deve estar e continuar sendo de luta, por meio de associações, de sindicatos, de informações, de debates, de leituras, de pesquisas, por melhores condições de trabalho docente, de valorização profissional. (TEIXEIRA; BRITO, 2017, p. 9)

Em relação aos retornos para a escola, encontramos nas narrativas das professoras falas que evidenciam momentos e sentimentos de angústia, desilusão e estranhamento com a profissão, associados a algumas condições de trabalho que lhes são apresentadas no momento do regresso.

Algumas professoras explicitaram acreditar que, ao retornarem, poderiam auxiliar suas unidades escolares por meio de uma atuação de orientação, com os colegas e gestão, no entanto, elas tiveram que se adequar a novas rotinas e a lecionar disciplinas 
fora de suas áreas de formação, aliadas ao enfrentamento de problemas sociais que se agravaram no ambiente escolar durante o período de afastamento. É interessante observar que cada professora descreveu esse momento de modo muito particular, no qual as narrativas sobre o regresso à escola e à sala de aula, apresentam elementos diferenciados, que estão diretamente associados às identidades e subjetividades das professoras.

[...] meu choque maior talvez tenha sido em relação à sala de aula, porque você fica fora por dois anos, e quando você retorna, você acredita que você vai encontrar algo diferente. Mas você não encontra, você encontra seus alunos em versões pioradas, em termos de disciplina, e às vezes a gente fica assim, sem saber o que fazer, porque são questões que estão fora de seu alcance [...] Em relação ao retorno depois do mestrado eu tomei um choque muito grande de realidade [...] no município quando retornei, eu tive que enfrentar uma situação que eu não queria. Porque, quando eu saí, para o mestrado, eu ensinava ciências, quando eu retornei eu tive que lecionar educação para a Sexualidade. [...] no mestrado a gente viu uma disciplina com o prof. "A", onde a gente viu um pouco dessa questão da sexualidade. Então, procurei alternativas de trabalhar, e no mesmo momento fui convidada a participar de uma pesquisa nesta área de conhecimento, junto ao mestrado, como colaboradora. $\mathrm{E}$ aí eu tive muito suporte, tive o contato com muitos materiais, e realmente eu comecei a gostar, não tive o que reclamar, tanto que terminei o ano de 2016 solicitando a direção da escola que no ano de 2017 eu continuasse lecionando a disciplina Educação para a Sexualidade [...] Você sai com mil ideias. Você vai fazer o projeto tal. Você vai fazer publicação. Você vai escrever artigo, participar de eventos. Mas quando você volta para rotina de professor de Educação Básica, e você tem que estar 7 horas na sala de aula, sair 11 horas, entrar na outra as 13 horas, sair 17:30 horas, com vários planejamentos para você fazer não é possível. Ainda que eu só ensine no nível médio e na minha disciplina, eu tenho que correr atrás! Porque tem questões de ENEM, de atualidades, que eu tenho que buscar. Então, assim, você não acha tempo para academia, porque o tempo que você tem para academia é o tempo que você tem para em casa para sua família, então você tem que escolher [...]. (Informação verbal 1 - Excerto da Narrativa de Anita) ${ }^{6}$

[...] Mas aos poucos eu estou retomando isso aí, porque assim, a gente também tem uma instabilidade estadual, um ano você trabalha com uma disciplina, no outro você não sabe se você vai ficar com aquela disciplina, por conta de número de alunos que diminui, ou coisa desse tipo. E ano passado eu comecei a trabalhar à noite em outra escola, justamente por conta de ter ficado excedente na escola que eu estava. Eu estou trabalhando com EJA, matemática e física. Então, realidades diferentes,

\footnotetext{
6 Trechos retirados de narrativas de professores que participaram da pesquisa. As entrevistas foram realizadas entre os anos de 2017 e 2018 (junho). As entrevistas na íntegra podem ser encontradas na dissertação de Martins (2018). Ver em referência.
} 
então estou bastante sobrecarregada este ano. De manhã trabalho com ensino fundamental, tarde com ensino técnico e à noite com ensino do EJA. Então, eu estou com esses três segmentos e preciso dar conta de tudo de alguma forma, eu preciso dar conta [...]. (Informação verbal 2 Excerto da Narrativa de Viviane)

[...] Quando eu terminei o mestrado eu me dei conta de que eu vivia em um mundo, o mundo acadêmico. E é lindo. Vivia no mundo que não tinha muita correlação como o trabalho. Após o mestrado eu fiquei desempregada, eu fiquei desempregada uns 6 meses. Eu fiquei procurando trabalho, e nisso eu fui atuar em uma escola pública, eu consegui um contrato pelo estado, fiquei acho que uns oito meses. $\mathrm{Na}$ época não foi nem REDA, foi PST (Prestação de Serviço Temporário). Porque você sai de um campo, em que você tem bolsa, você tem incentivo, tem financiamento para estudar tranquilo. Mas isso acaba, e quando você não tem algo fixo, como a questão do concurso, você vai procurar algo para fazer, e na época não tive, não teve nenhum concurso de nível superior, aqui na UESB [...]. (Informação verbal 3 - Excerto da narrativa de Ruth)

[...] o regresso também é complicado! Porque mais uma vez é um envolvimento psicológico da pessoa. O que eu vou te contar agora, partiu, acho, que mais de mim, do que dos outros. [...] Quando eu voltei eu tinha uma sensação que eu tinha ficado de fora de tudo durante um ano, e eu cheguei ali no meio do ano sabe, e caí de paraquedas. O mais agravante foi que eu tinha acabado de voltar nessa escola, eu tinha sido removida em no início de 2015. Só estive nesta escola cinco meses na escola construindo relações. Em cinco meses você não constrói nada muito sólido. Aí fiquei um ano fora. Quando retornei, teve aquela questão de conversa: - "oh, fulano saiu para um mestrado.". Tem isso né?! Tem um olhar sobre isso também. Não sei se de repente alguém pensa assim: “Tá de licença, tá em casa!" Não sei. Quando eu voltei, eu senti, e por isso que eu falei que o sentimento é meu, mas eu senti que eu estava isolada. Tipo, todo mundo estava bem amigo, tinha chegado professor novo, e eu não tinha construído relações muito sólidas. Passei poucos meses antes de sair de licença. Uma professora que chegou depois de mim e já estava toda enturmada sabe, eu me senti deslocada, aí eu me fechei no meu mundo ali. Então, juntou o sofrimento de lidar com os alunos, estava me sentindo insegura, e o sofrimento em me sentir uma estranha ali, que todo mundo estava unido. Na hora do intervalo e todo mundo conversando, aquela algazarra, não sei o que, não sei o que... e eu ficava meio assim né, cheia de dedos. Aí piorava quando algum colega falava: "Olha a mestre! Chegou a mestre". Poxa, para quem não sabe que eu estava num mestrado vai me colocar naquela situação chata: “Oh, ela é mestre!", um negócio chato. Você fica naquela coisa, assim, parecendo que você está num nível maior que os outros, entendeu? E quem fala assim não pensa assim, está fazendo com brincadeira. É teu amigo, mas os outros podem olhar desse jeito. Eu ficava com medo do outro olhar para mim [...]. (Informação verbal 4 Excerto da narrativa de Simone) 
As professoras Anita, Viviane e Simone narram sobre o sentimento de deslocamento em relação à realidade escolar. A falta de estabilidade em relação às condições para o exercício da profissão, em que temos desde alterações em carga horária, disciplinas, ambiente escolar, processos de rejeição por parte de alunos e colegas de trabalho. No entanto, também relataram que buscaram alternativas para se adequar a tais situações e superá-las por meio de suas novas bagagens teóricas adquiridas no curso do mestrado, e desse modo, realizarem uma atuação que lhes permita estar e permanecer na profissão de modo satisfatório, sem que a qualidade de ensino fosse deixada em segundo plano.

Anita teve, em seu retorno, que ministrar aulas de educação para a sexualidade, e o que a princípio foi um problema, logo foi superado por meio dos conhecimentos discutidos no mestrado. As relações entre os colegas em suas unidades escolares não se alteraram, e esta professora relata que algumas novas parcerias se estabeleceram nas escolas. A formação no mestrado pode ter promovido disposição para trabalhos em grupo, de modo mais consolidado, como apontam Carvalho e Pérez (2003), uma formação adequada incide na melhoria do ensino realizado pelos professores:

[...] Eu percebi um reconhecimento da escola, mas valorização você não percebe. Não. Eu não percebo [...] eles querem professores com formação na escola. Também é o objetivo da escola ter pessoas com formações. Uma coisa é que eles gostam de ter professores com um bom currículo, mas assim (longa pausa), não me fizeram muitas cobranças. Não posso dizer que fizeram muitas cobranças. (pausa pequena) Até então não, não com muitas expectativas, muitas cobranças. No estado buscaram me colocar em outras funções, que acharam que eu poderia com minha formação, estar ajudando ainda mais a escola. Já no município a única coisa que eu percebo, realmente, é quando anunciam no começo do ano para falar aos professores iniciam assim: "Nós temos uma professora que é mestra aqui.". Só isso. Mais nada. [...] (Informação verbal 5 - Excerto da Narrativa de Anita)

[...] No início, quando eu voltei, achei que as relações pioraram, tanto que me isolei, tanto que eu me isolei. Agora, se você pensar a maneira como você vem depois do mestrado, em relação a formação, o ser professora, por estar naquele ambiente ali, e servir àquela comunidade, acho que isso melhorou muito o entendimento que eu tinha do que era docência num papel ali, aí sim mudou de novo, mudou de novo porque a relação com esta menina mesmo, mudou, depois que ela fez esse, esse texto para mim, mas esse texto só veio porque eu mudei, é isso, eu mudei depois do mestrado. Não que eu não fizesse, mas o que eu fazia era 
muito mais focado para minha disciplina, sempre fiz [...]. (Informação verbal 6 - Excerto da Narrativa de Bertha)

As professoras relatam que não houve grandes considerações por parte da comunidade escolar em relação ao retorno, não lhes foi questionado nada sobre o processo, ou se de algum modo a formação poderia contribuir com as práticas docentes do professor, com a atuação dos colegas, com a gestão, ou com as relações existentes na comunidade escolar. Nóvoa (2009) aponta que são justamente essas interações, no ambiente escolar, entre os educadores, que forjam o sentimento de pertença, a identidade do professor e o que leva esses profissionais a atuarem com mais comprometimento. Na fala da colaboradora Bertha, que leciona em uma escola com regime diferenciado, militar, fica evidente que a rotina e as normas de trabalho são tidas como imutáveis, o que denota nessa professora um sentimento de absoluta conformação ao que está posto. Essas condições de trabalho não promovem uma autonomia no fazer docente, o que se contrapõe à intencionalidade inicial da formação continuada mestrado acadêmico, o qual busca uma atuação voltada para um ensino, e, neste caso, especificamente o ensino de Ciências, que permita a professores e alunos uma atuação mais efetiva e crítica em sociedade (BRASIL, 2017).

[...] É muito difícil, muito raro, você ver pós-doutores vindo concorrer aqui em Jequié, para você ver que são questões que perpassam a política, não tem para onde correr, você não tem oportunidades, entendeu, e aí eu fiquei sem essas oportunidades, aí o que é que você vai fazer, vai fazer aquilo que aparece né, você vai ficar sem trabalhar? "- Ah, porque eu sou mestre, eu não quero trabalhar em escola"..., então (risos), as contas vencem né, a gente precisa sobreviver, “- Ah, porque eu sou mestre, sou mestre e não posso trabalhar na educação básica, porque eu tenho um título" (risos), isso não conta na hora de pagar as contas, né assim?! Então, isso é a realidade, então você sai de um mundo, que é o mundo acadêmico, e vai para um mundo do trabalho, que nem sempre tem as oportunidades que você espera, e no meu caso não teve, entendeu, então o que foi que eu fiz, eu fui trabalhar em escola pública com educação básica, aí fiquei... acho que uns oito meses, no ano acho que de 2015, 2015, no ano de 2016 eu fui convidada por uma escola particular [...]. (Informação verbal 7 - Excerto da Narrativa de Ruth)

A colaboradora Ruth, para ingressar na formação do mestrado, teve de pedir desligamento da rede de ensino estadual, na qual atuava em sistema de Regime Especial 
de Direito Administrativo - REDA, o qual é valido por dois anos e seis meses, podendo ser renovado por mais dois anos. Após o término do processo formativo, ela não conseguiu de imediato espaço no mercado, e o vínculo obtido foi o regime de Prestação de Serviço Temporário - PST, seis meses após a conclusão do mestrado. Esses dois regimes se diferenciam muito em relação a condições de trabalho e valores de remuneração, sendo este segundo um vínculo que oferece condições ainda mais precárias para atuação docente. Essa colaboradora se direcionou para a rede privada de ensino. Seu relato nos causou extrema indignação, pois a ela descreve situações que vivenciou, e ainda, segunda esta, vivencia assédio sexual e moral por parte de um dos gestores da unidade escolar. Ainda completa afirmando que vem sofrendo nos últimos dois anos nesse ambiente, mas que até o momento da coleta de sua narrativa, esse vínculo era a única opção para o exercício da profissão nas redes de ensino na cidade de Jequié.

[...] porque uma situação dessa é muito constrangedora. É aí que você vê que parece que tudo o que você aprendeu, tudo o que você estudou, não vale muito a pena entendeu?! É uma questão difícil, e até semana passada ele me chamou, e falou que não sabia se eu ia continuar na escola, e eu falei tudo bem (pausa) porque o que ele quer é uma relação íntima comigo... então tudo isso a gente passa na educação, pode ter sido só eu. Mas, também, muitas podem ter passado por isso também né. $E$ você pode colocar, porque isso acontece, eu faço questão que você coloque, eu faço questão. E isso em uma escola privada. Então a educação é uma ferramenta de interesse, entende, infelizmente isso acontece. No setor público a gente pode ter sim, uma valorização financeira, um campo de trabalho maior, um incentivo. [...] (Informação verbal 8 - Excerto da narrativa de Ruth)

Sobre encontros e desencontros no retorno, a professora Simone relata um estranhamento que resultou em um processo de adoecimento, que foi diagnosticado e tratado. Segundo a professora, esse processo foi também resultado da atuação que passou a desenvolver no primeiro ano do mestrado, quando teve que conciliar trabalho com a formação. Ela utiliza o termo “[...] a formação me deformou [...]” para descrever um processo de descolamento com a profissão, no qual passou a atuar de modo mais técnico. Em seu retorno, vivenciou a rejeição de alunos, que se opuseram ao afastamento da professora que lhe substitui no período de afastamento para o mestrado. Ela descreve que atualmente, tal dificuldade está sendo superada por meio de medicamentos e terapia. 
[...] Aí eu fiquei um ano de licença. Volto para sala de aula em junho de 2016, parecia que eu nunca tinha dado uma aula. Entrei na sala, minha perna não tremia não, ela balançava assim, oh (risos e demonstração). Um medo. Uma coisa que eu não sei o que era. Insegurança! E eu entrei. A primeira aula que eu dei, eu não esqueço, foi numa sala de nono ano, oitava série. Uns meninos enormes. E eu tinha ido de sapatilha (risos). Hoje, analisando né, essa ideia de eu estar pequena, e eles estarem grandes. Eu estava com medo, me sentindo pequena, em outro sentido, que loucura! Aí eu fiquei. Menina, eu demorei um tempo bom, para me recuperar. [...] Eu procurei o médico. Fiz algumas consultas e tal. Aí ele chegou a conclusão do que eu já sabia, né! Que eu estava com um TOC e transtorno de ansiedade. E várias outras coisas juntas, misturadas, estava piorando esse quadro de insegurança, entendeu?! E por isso esse retorno foi tão difícil depois do mestrado [...] parece que... eu desaprendi. Desaprendi [...] Eu estava com medo, entendeu?! E eu não sou uma pessoa de ter medo de nada. Eu sou super... sabe?! Bem resolvida com tudo. E passei por isso. Eu aprendi a ser professora de novo, duas vezes. Lá no início e agora, no retorno. Depois desse retorno parece que comecei de novo. É, eu nunca pensei nisso. É. Realmente. Você chega com uma bagagem diferente [...]. (Informação verbal 9 - Excerto da Narrativa de Simone)

Essa fala nos permite inferir que a professora vivenciou um processo de desconstrução de práticas pedagógicas que faziam parte de sua atuação. Esse processo fomentou sentimentos de incertezas, insegurança, inquietações, receios, mas como ela mesma narra, após um período para acomodação dos novos saberes, construiu uma nova possibilidade de ensino com os conhecimentos que foram apreendidos na formação stricto sensu.

\section{Enfretamentos e perspectivas}

Ao narrarem sobre o retorno para o campo do trabalho, as professoras apontaram alguns aspectos, como a instabilidade nas condições de trabalho no retorno. Algumas professoras foram realocadas, sendo remanejadas em novas unidades escolares, em cursos técnicos; em outros casos, não há garantias no retorno de lecionar dentro da área de conhecimento. Em algumas falas foi registrado sentimento de frustração para com as lembranças do retorno para as escolas e para a sala de aula.

Discorrem, também, que não há quase nenhum tipo de valorização ou reconhecimento por parte de seus pares, da gestão da Unidade Escolar ou mesmo dos 
órgãos aos quais elas estão vinculadas, sobre a titulação alcançada, voltada para a aplicabilidade dos novos saberes dessas professoras, mas que há um reconhecimento sobre o esforço, e sua dedicação para a obtenção do título. Elas argumentam que não criaram expectativas para o processo de retorno, mas ao mesmo tempo descrevem que esperavam poder contribuir de algum modo com a rotina da escola, com as atividades desenvolvidas, e até mesmo em desenvolverem uma formação para seus pares. Percebemos nessas falas que as professoras apontam que os conhecimentos adquiridos não são mais bem aproveitados no seu ambiente de trabalho na busca da superação de problemas.

Esses aspectos apontados nas narrativas também nos fazem afirmar que há uma lacuna complexa a ser preenchida no que tange aos interesses comuns entre os envolvidos no processo de afastamento de um docente para cursar um mestrado e/ou doutorado. Necessário se faz a reflexão coletiva sobre o que representa uma formação stricto sensu para professores da rede básica e como isso pode ser somado para a melhoria dessa educação.

A convergência entre resoluções, estatutos e processos formativos para pensar e orquestrar a vida do professor ainda é uma necessidade. Sentir-se valorizado, comprometer-se com o título e o que ele exige deve ser um entendimento coletivo. Pensamos ainda que, caso não aconteça tal convergência, o professor termina por não ter como desaguar de outra forma o seu potencial formativo adquirido durante as atividades do mestrado, o conhecimento adquirido, uma vez não mobilizado no interior da escola, termina por obsoleto. Esse é um enfretamento necessário nesse novo cenário formativo que se desenha. 
ANDRÉ, Marli Eliza Dalmazo Afonso de. Mestrado profissional e mestrado acadêmico: aproximações e diferenças. Revista Diálogo Educacional, Curitiba, v. 17, n. 53, p. 823-841, 2017. Disponível em: <http://www.researchgate.net/publication/ 322782653_MESTRADO_PROFISSIONAL_E_MESTRADO_ACADEMICO_APROXIMACOES_E _DIFERENCAS>. Acesso em: 14 mar. 2017.

BRASIL. Conselho Nacional de Educação. Resolução $n^{\circ}$ 7, de 11 de dezembro de 2017. Estabelece normas para o funcionamento de cursos de pós-graduação stricto sensu. Brasília, 2017. Disponível em: <http://portal.mec.gov.br/docman/dezembro-2017pdf/78281-rces007-17-pdf/file>. Acesso em: 28 dez. 2017.

BRASIL. Coordenação de Aperfeiçoamento de Pessoal de Nível Superior- CAPES. Mestrado profissional, mestrado acadêmico e doutorado. Brasília, DF, 2007. Disponível em: <https://www.capes.gov.br/images/stories/download/artigos/Artigo_30_08_07.pdf>. Acesso em: 30 abr. 2017.

BRASIL. Conselho Nacional de Educação. Resolução CNE/CP n. 02/2015, de $1^{\circ}$ de julho de 2015. Define as diretrizes curriculares nacionais para a formação inicial em nível superior (cursos de licenciatura, cursos de formação pedagógica para graduados e cursos de segunda licenciatura) e para a formação continuada. Diário Oficial [da] República Federativa do Brasil, seção 1, n. 124, p. 8-12, Brasília, DF, 02 de julho de 2015. Disponível em: <http://portal.mec.gov.br/docman/agosto-2017-pdf/70431-res-cne-cp-002-03072015pdf/file>. Acesso em: 26 set. 2017.

BRASIL. Lei $\mathbf{n}^{\circ} \mathbf{1 3 . 0 0 5}$, de 25 de junho de 2014. Aprova o plano nacional de educação (PNE) e dá outras providências. 2. ed. Brasília: Câmara dos Deputados, Edição Câmara, Brasília, DF, 2015. Disponível em: <http://pne.mec.gov.br/18-planos-subnacionais-de-educacao/543plano-nacional-de-educacao-lei-n-13-005-2014>. Acesso em: 19 out. 2017.

BRASIL. Decreto $n^{\circ}$ 6.755, de 29 de janeiro de 2009. Institui a política de formação de profissionais do magistério da educação básica, disciplina a atuação da coordenação de aperfeiçoamento profissional de nível superior - capes no fomento a programas de formação inicial e continuada, e dá outras providências. Brasília, DF, 2009. Disponível em: <http://www2.camara.leg.br/legin/fed/decret/2009/decreto-6755-29-janeiro-2009-585786norma-pe.html>. Acesso em: 10 fev. 2017.

BRASIL. Ministério da Educação. Secretaria de Educação Básica. Orientações gerais. Brasília, DF, 2006. Disponível em: <http://portal.mec.gov.br/seb/arquivos/pdf/Rede/ catalg_rede_06.pdf>. Acesso em: 25 jun. 2016.

Brasil, Ministério da Educação. Plataforma Sucupira. Coordenação de Aperfeiçoamento de Pessoal de Nível Superior. Brasília: 2018. Disponível em: <https://sucupira.capes.gov.br/sucupira/public/consultas/coleta/programa/quantitativos/q uantitativoRegiao.jsf;jsessionid=IpC19tcuSCVdbQWNHKsjYjWE.sucupira-213>. Acesso em: 05 de junho de 2018. 
BRASIL. Resolução CNE/CP 1/2002, de 18 de fevereiro de 2002. Diretrizes curriculares nacionais para a formação de professores de educação básica, em nível superior, curso de licenciatura, de graduação plena: Brasil PNE 2001-2010. Brasília, DF, 2002. Disponível em: <http://portal.mec.gov.br/cne/arquivos/pdf/rcp01_02.pdf>. Acesso em: 25 jun. 2016.

BRASIL. Parecer CNE/CP 009/2001. Diretrizes curriculares nacionais para a formação de professores da educação básica, em nível superior, curso de licenciatura, de graduação plena. Brasília, DF, 2001. Disponível em: <http://portal.mec.gov.br/cne/ arquivos/pdf/rcp01_02.pdf>. Acesso em: 26 jun. 2017.

BRASIL. Ministério da Educação. Propostas de diretrizes para formação inicial de professores da educação básica em cursos de nível superior. Brasília, DF, 2000. Disponível em: <http://portal.mec.gov.br/cne/arquivos/pdf/basica.pdf>. Acesso em: 20 set. 2016.

BRASIL. Lei 9.394 de diretrizes e bases da educação nacional. Brasília, DF, 1996. Disponível em: <http://www.planalto.gov.br/ccivil_03/LEIS/L9394.htm>. Acesso em: 15 abr. 2016.

BRASIL. Lei $\mathbf{n}^{\circ} \mathbf{7 . 0 4 4}$, de 18 de outubro de 1982. Fixa diretrizes e bases para o ensino de $1^{\circ}$ e $2^{\circ}$ graus, e dá outras providências: lei de diretrizes e bases da educação nacional. Brasília, DF, 1982. Disponível em: <http://www2.camara.leg.br/legin/ fed/lei/1980-1987/lei7044-18-outubro-1982-357120-publicacaooriginal-1-pl.html>. Acesso em: 01 dez. 2017.

BRASIL. Lei $\mathbf{n}^{\circ}$ 5.692, de 11 de agosto de 1971. Fixa diretrizes e bases para o ensino de $1^{\circ} \mathrm{e}$ $2^{\circ}$ graus, e dá outras providências: lei de diretrizes e bases da educação nacional. Brasília, DF, 1971. Disponível em: <http://www2.camara.leg.br/legin/fed/lei/1970-1979/lei-5692-11agosto-1971-357752-publicacaooriginal-1-pl.html>. Acesso em: 01 dez. 2014.

BRASIL. Lei n $^{\circ}$ 4.024, de 20 de dezembro de 1961. Fixa as diretrizes e bases da educação nacional: lei de diretrizes e bases da educação-Idb. Brasília, DF, 1961. Disponível em: <http://www2.camara.leg.br/legin/fed/lei/1960-1969/lei-4024-20-dezembro-1961-353722publicacaooriginal-1-pl.html>. Acesso em: 14 set. 2014.

CARVALHO, Ana Maria Pessoa de; GIL-PÉREZ, Daniel. Formação de professores de ciências: tendências e inovações. 7. ed. São Paulo: Cortez, 2003.

CHIMENTÃO, Lilian Kemmer. O significado da formação continuada docente.

Universidade Estadual de Londrina. In: CONGRESSO NORTE PARANAENSE DE EDUCAÇÃO FÍSICA ESCOLAR, 4. Trabalhos apresentados [...]. Londrina, 2009. Disponível em: <http://www.uel.br/eventos/conpef/conpef4/trabalhos/comunicacaooralartigo/artigocom oral2.pdf $>$. Acesso em: 14 set. 2017

CORTELA, Beatriz Salemme Corrêa. Formação inicial de professores de física: fatores limitantes e possibilidades de avanço. Tese (Doutorado em Educação para Ciência) Universidade Estadual Paulista Júlio de Mesquita Filho, Pós-Graduação em educação para a Ciência, Bauru. 2011. Disponível em: 
<https://repositorio.unesp.br/bitstream/handle/11449/

90965/cortela_bsc_dr_bauru.pdf?sequence=1\&isAllowed=y>. Acesso em: 16 de jan. 2018.

CUNHA, Ana Maria Oliveira; KRASILCHIK, Myriam. A formação continuada de professores de ciências: percepções a partir de uma experiência. In: XXIII REUNIÃO ANUAL DA ANPED, 23. Anais eletrônicos [...] Caxambú, 2000. Disponível em: <http://www.anped.org.br/sites/default/files/gt_08_06.pdf >. Acesso em: 11 fev. 2017.

GATTI, Bernadete Angelina. Análise da política pública para formação continuada no Brasil, na última década. Revista Brasileira de Educação, Rio de Janeiro: Anped, v. 13, n. 37, p. 57-70, jan./abr. 2008. Disponível em: <http://www.scielo.br/scielo.php?script= sci_arttext\&pid=S1413-24782008000100006\&lng=pt\&tlng=pt/>. Acesso em: 25 mar. 2017.

GATTI, Bernadete Angelina; BARRETO, Elza Siqueira de Sá. Professores: aspectos de sua profissionalização, formação e valorização social. Brasília, DF: UNESCO, 2009.

IMBERNÓN, F. Formação continuada de professores. Porto Alegre: Artmed, 2006.

MARTINS, Regiane Barreto. Tornar-se mestre e regressar ao campo de trabalho: narrativas de professores de ciências. Dissertação (Mestrado em Educação Científica e Formação de professores) - Departamento de Biologia, Universidade Estadual do Sudoeste da Bahia. Jequié, Bahia. 2018.

MELO, Pedro Antônio de; LUZ, Rodolfo Joaquim da. A formação docente no Brasil. Florianópolis: INPEAU, 2005.

MORORÓ, Leila Pio. A formação de professores em serviço: o PARFOR na Bahia. In: ENCONTRO NACIONAL DE DIDÁTICA E PRÁTICAS DE ENSINO, 16. Campinas: Ed. Junqueira \& Marin, 2012. Livro 2. p. 3509-3521.

NARDI, Roberto; CORTELA, Beatriz Salemme Cortela. A constituição de um perfil indenitário de um curso de Física. In: NARDI, R; CORTELA, B. S. C. (Org.). Formação inicial de professores de Física em universidades públicas: estudos realizados a partir de reestruturações curriculares. 1. ed. São Paulo. Editora livraria da Física. 2015.

NÓVOA, António Manuel Seixas da. Professores: imagens do futuro presente. Educa, Lisboa, 2009.

PEREZ, Geraldo, Formação de professores de matemática sob a perspectiva do desenvolvimento profissional. In: BICUDO, Maria Aparecida Viggiani (Org.). Pesquisa em Educação Matemática: concepções e perspectivas. São Paulo: Unesp, 1999.

RIBEIRO, Renato Janine. O mestrado profissional na política atual da Capes. Revista Brasileira de Pós-Graduação, v. 2, n. 4, p.8-15, jul. 2005.

SAVIANI, Dermeval. História das ideias pedagógicas no Brasil. 3. ed. Editora Autores Associados Edição, 504 p., 2009. 
TEIXEIRA, Maria Soares da Silva; BRITO, Talamira Taita Rodrigues. Os dilemas da profissão professor de biologia na educação básica. In: ENCONTRO NACIONAL DE PESQUISA EM EDUCAÇÃO EM CIÊNCIAS, 11., 2017, Florianópolis. Anais [...]. Florianópolis: UFSC, 2017, p. 110. Disponível em: <http://www.abrapecnet.org.br/enpec/xi-enpec/anais/resumos/R24781.pdf>. Acesso: 26 dez. 2018.

URZETTA, Fabiana Cardoso; CUNHA, Ana Maria de Oliveira. Análise de uma proposta colaborativa de formação continuada de professores de ciências na perspectiva do desenvolvimento profissional docente. Ciênc. educ., Bauru, v. 19, n. 4, p. 841-858, 2013. Disponível em: <http://www.scielo.br/scielo.php?pid=S151673132013000400005\&script= sci_abstract\&tlng=pt>. Acesso em: 20 jul. 2017.

Universidade do Estado de Santa Catarina - UDESC

Programa de Pós-Graduação em Educação - PPGE

Revista Linhas

Volume 20 - Número 43-Ano 2019 revistalinhas@gmail.com 